\title{
INFLATION SPIRALS AND SELF-REPLICATION OF INFLATION
}

\author{
Tatyana Kotcofana, ${ }^{1}$ Alexander Protasov, ${ }^{2}$ Polina Stazhkova St. ${ }^{3}$
}

\begin{abstract}
Inflation is a complex socio-economic phenomenon, whose formal sign is the depreciation of money. Most often it is expressed in the form of rising prices, although it also has other manifestations. The economic substance of this phenomenon lies in the area of public reproduction and the socio-economic relations about the distribution of public product and public wealth. In this article, the self-replicating nature of inflation is shown and genesis and evolution of inflationary process at all stages of public reproduction are analyzed. It is shown that each of the stages has the mechanisms capable of generating inflationary potential. The category of "inflationary spiral" is explained in more detail, because it cannot be presented only by a traditional "costs - prices" mechanism. Inflationary spirals can be observed at any stage of the reproduction process, making the task of managing inflation even more difficult. It causes the need for the complex accounting of all the variety of factors of the inflationary process and the inflation consequences in the formulation of an economic policy.
\end{abstract}

JEL Classification Numbers: C10, E31; DOI: http://dx.doi.org/10.12955/cbup.v5.931

Keywords: inflation; reproduction process; price; cost; inflationary spirals; economic policy.

\section{Introduction}

Economic development of virtually every country takes place against the background of inflation with various causes that manifest differently, depending on the circumstances of time and place. Inflation is complex and heterogeneous in its causes, mechanisms and consequences. It is a socio-economic phenomenon. It creates difficulties for the study of the apparent surface-level characteristics of the inflation process as well as its inner structure and qualitative characteristics. The interpretation of inflation as a multifactorial phenomenon focuses on a comprehensive study in order to identify the roles of all the factors that are constantly changing interactions with each other and creating different inflation "pulses" and "pushes." This approach prevents hypertrophy in evaluating some aspects and underestimation or total disregard of others. The methodology is based on the idea that there are no disconnected processes of inflation of prices governed by different unconnected determinants. Price increase may be caused by factors of money circulation or factors of the goods supply side. In the course of this single process parameters are tightly intertwined and one or the other parameter can become a priority in any given moment.

In our view, analysis of the genesis of the inflation process in a modern economy begins with accepting the depreciation of money and the associated rise in prices as only formal signs of inflation, while its economic content lies in the deeper areas related to the reproduction process and social relations over the product produced. Inflation can be interpreted as a monetary manifestation of imbalances already existed and/or deliberately supported within the national economy and which leads to an excess in the money supply. Purely monetary factors of inflation only frame or strengthen existing imbalances, but in any case, they are not the main cause of inflation. The approach is commonly referred to as reproductive, since it allows you to look at any economic phenomenon and its causes through the prism of all stages of the reproductive process, while stages are analyzed in their relationship and interaction. This approach is suitable for analysis of the inflation process with its interconnectedness and interdependence thus revealing their deepest nature and patterns of development. Economic policies based on this extended analysis of the causes of inflation and its impact on the economy is potentially more effective (Kotcofana, 2007).

\section{Methodology: reproduction approach}

The reproductive approach to the analysis of inflation is based on the fact that all stages of the reproductive process are interrelated, and each of them contains a certain inflation potential. It is important to bear in mind the following points:

1. Inflation is so complex it is not rare for causes and effects to switch places. Sometimes the same phenomenon acts simultaneously as the cause of inflation and its consequence. This

\footnotetext{
${ }^{1}$ St. Petersburg State University, t.kotsofana@ spbu.ru

${ }^{2}$ St. Petersburg State University, a.protasov@ spbu.ru

${ }^{3}$ St. Petersburg State University. p.stazhkova@ spbu.ru
} 
characteristic of the process is reflected in the term "inflationary spiral" that is often used by economists (Tsatsulin et al., 2016). Examples of inflationary spirals are shown below. They are not limited to the traditional scheme of "wages-prices" (Xiang Baolin, \& Xiao Xiaoyong, 2009; Pressman \& Holt, 2008) or the broader one "costs-prices."

2. Although the use of the reproductive approach does not reject quantitative methods of analysis, the emphasis is on identifying qualitative relationships and patterns of economic development. Quantitative, functional relations play a subordinate role. Under the reproductive approach mathematical calculations and illustrations are applied primarily to provide greater reasoning and clarity of logical conclusions.

\section{Production stage}

The analysis of inflationary processes at the production stage is related to factors affecting the value of the commodity (so called primary price-forming factors). Such factors include a real rise in cost of production due to increased prices on raw materials, equipment and tools, decrease in labour productivity and decreased efficiency of resource use, as well as degradation of technology. The effects of the inflationary spiral can be most clearly demonstrated in the sphere of production. Inflation leads to the rise in costs of production factors; it leads to increased costs of final products; it then leads to the next circle of inflation and increased costs of production factors. Thus, the crucial condition of expanded reproduction is the availability of credit, real interest rates for the non-financial sector and the volume of loans for the non-financial sector (Domashchenko, 2016). During inflation, the dynamics of bank interest is divorced from the dynamics of the profitability of the real sector; it leads to sharp fluctuations in interest rates and the levels of profitability. Random combinations of such fluctuations can completely eliminate or substantially reduce the profitability of production, but it may also increase profitability, regardless of technical and economic and organizational shifts in production. In order for the creditor to preserve money and get the interest, the nominal interest rate should exceed the rate of price growth. Usually it is calculated according to the formula: $R=r+\pi+r \pi$, where $\mathrm{R}$ is nominal interest rate, $\mathrm{r}-$ real interest rate, and $\pi$ - inflation rate. The result of nominal interest rate growth is an artificial but real money shortage in the economy. It is harmful for production processes and hence production shrinks. During high tempos of inflation, the opposite phenomenon occurs: real interest rate plummets to negative levels: $r=\frac{R-\pi}{1+\pi}<0$, если $\pi>R$

It seems negative interest rate should contribute to the recovery of production, but in fact this does not happen, since such rate is not profitable for banks. Moreover, the credit period is reduced to one or two months due to increasing risks. It does not fit into the technological terms of turnover of funds at enterprises. It is important to consider that current money reserves under inflationary conditions are going down in value; it increases the demand for loans. There is a spiral: inflation leads to slowing down of business activity and a reduction in production, and this, in turn, is one of the factors of inflation.

\section{Distribution stage}

At the stage of distribution, our attention is focused primarily on secondary price-forming factors that deflect the price from value. This stage is of key importance for the analysis of inflation processes, because, in our opinion, the very nature of inflation is rooted in the social conflict over the distribution of the results of production between different social groups and the strata of society. More detailed can be found in Protasov (2011). Such conflicts are present in any society under any socio-economic system. However, the condition for its realization is unequal possibilities of various economic agents, social groups and countries in relation to the results of production due to prevailing economic and institutional structures. As soon as at least one actor gets enough of the economic power to make an attempt to redistribute wealth to one's own advantage this conflict transforms from potential tendency into real actions generating inflationary impulses.

The distribution stage plays an important role in spreading inflationary impulses generated at the production stage and, consequently, in the further unwinding of inflationary spirals. For example, if we consider the process of price growth as a result of increase in production costs, then in accordance with the equation of the input-output model, this process has to be fading rather than self-replicating, 
since the costs are only a part of any price and their growth should influence the chain of counterparties of exchange less and less. The formula for a sequential change in the costs for interindustry exchange, for example, due to monopolistic increase of prices in the 1st sector, will look as follows: $P_{i}=P_{1}+\alpha_{1} \times \alpha_{2} \ldots \alpha_{i-1} \times\left(K_{1}-1\right)$, where $\mathrm{i}$ is the industry number $(\mathrm{i}=1, \ldots, \mathrm{m}$, and $\mathrm{m}$ is the number of the last of the entire set of industries under consideration). For example, raw materials are supplied from every $\mathrm{i}$-th industry to $(\mathrm{i}+1)$ th. $\mathrm{K}_{\mathrm{t}}$ is the rate of price growth in the 1st industry;

$\alpha_{\mathrm{i}-1}-$ the share of costs in the price of the $\mathrm{i}$-th industry for the purchase of raw materials in the $\mathrm{i}$-th industry; $\mathrm{P}_{1}$ and $\mathrm{P}_{\mathrm{i}}-$, the base price of goods in the 1 st and current price in the $\mathrm{i}$-th industries respectively. If we assume $\mathrm{P}_{1}=1, \mathrm{~m}=10, \alpha_{1}=\alpha_{2}=\ldots=\alpha_{\mathrm{i}-1}=0.5, \mathrm{~K}_{1}=2$, then we have $\mathrm{P}_{\mathrm{i}}=1.002$. That is, the final increase in price at the tenth stage of the exchange of goods for money was, in fact, zero. An example is taken from (Nusratullin, 2010)

Meanwhile, as has already been mentioned, spiral-like self-reproducing effects of price increases are observed in practice. These effects occur due to the fact that the value formation chains usually are not strictly linear. Both economic agents-initiators of price increases and a certain number of consumer subjects buy the same goods from the same suppliers in one link of the technological chain of interindustry exchange. The example of economic agents-initiators of price increases is the monopolist, which raised the price of electricity supplied. However, they lose part of their "normal" value added, and in order to compensate losses they overestimate their own prices or request state subsidies and preferential loans, or get stuck in non-payments. Any of these actions, parallel to the actions of the initiating subject, gives rise to a new increase in their own prices, which again leads to the emergence and a new redistribution of costs growth for "parallel" consumers. It is launching the inflationary spiral.

\section{Exchange stage}

The exchange stage acts as a platform for the realization of the inflationary potential generated in the production and distribution of the social product. The exchange stage by itself can also generate and is generating a variety of inflationary impulses. The competition between manufacturers today is mainly based on the frequent changes in the range and quality of products, huge trade, and advertising costs. There is an increase in costs in general and distribution costs in particular. This is largely facilitated by the differentiation of the product in conditions of competitive adaptation of the producer to the needs of the consumer. The role of packaging, advertising, and marketing methods is growing, and it obviously entails increased costs. (Pashkus, 2016) If previously in economic theory costs were primarily associated with production and were interpreted as the "production costs" category in the past century it has transformed into the "production and marketing costs" category. The category of market transactions costs (or "marketing costs") is one of the rapidly increasing components of production and marketing costs. According to American economists, the growth of these costs was the main reason for the rise in food prices. Already at the end of the twentieth century, they gave $90 \%$ of the total increase of final prices (Shershnev \& Larionov, 1999), and we can assume that today this trend is not only preserved but is also becoming more prominent.

The development and strengthening of the market positions of intermediary structures plays an important role in the genesis of the inflationary process at the stage of exchange. Intensive distribution systems operate in a modern economy. Consumer properties of the goods include time, place, form and methods of delivery. Thus, the proportion of intermediary costs is increasing; it means that overall prices are rising.

The traditional price structure is as follows:

$P F=P C+M+B+E T+V A T+(C M+B M+V A T)_{1}+\cdots+(C M+B M+V A T)_{n}+C S+B S+V A T$,

Where $\mathrm{PF}$ is the final selling price (retail price of the product), $\mathrm{PC}-$ production costs, $\mathrm{M}-$ cost of marketing for the manufacturer, B -profit of the manufacturer, ET - excise tax, VAT is a value added tax paid by all participants in a supply chain, $\mathrm{CM}$ - costs of the intermediary (wholesale) organization, $\mathrm{BM}$ - profit of the intermediary organization, $\mathrm{n}$ is the number of intermediaries in the chain, $\mathrm{CS}-$ costs of the organization of retail trade, BS - profit of the retail organization.

Modern conditions drive up costs of the component $\mathrm{M}$, as well as CM and BM, and VAT, paid by the intermediary link (in part due to increasing $n$ ). If the costs of the remaining components do not decrease, the price will increase. The inflationary spiral unwinds, because such a situation is observed 
for the majority of products, including intermediates, the price of which is included in costs of other products.

It is important to understand that in itself the presence of inflation in the economy largely determines the propensity of economic entities to speculative and intermediary activities to the detriment of production, and this in turn leads to the further unwinding of the inflationary spiral.

\section{Consumption stage}

The role of the consumption stage in generating the inflation potential of the economy is more important than it may seem at first glance. First of all, let us trace the relationship between inflation and various forms of use of the produced social product. The following forms can be distinguished: personal consumption (C), industrial consumption (I), savings of the population and the accumulation of enterprises (S), exports (E), losses (L). It sums up as $G D P=C+I+S+E+L$,

In the conditions of inflation, personal consumption becomes the main form of use of the created social product, since the productive use of it becomes much less profitable. The higher the inflation and the longer the production cycle are the fewer incentives entrepreneurs have for productive consumption. Devaluation of depreciation expenses leads to a reduction in opportunities to expand production and even maintain it at the same level. The nominal ratio of average propensities to save and to consume shifts in favor of consumption. If the nominal exchange rate remains at the same level, exports become less profitable, as domestic goods become more expensive relative to foreign-made goods. As a rule, losses increase during inflation. It can be caused both by objective reasons and by increased opportunities for dishonest statistical reports. As for Russia, the most important problem is the capital outflow from the country. According to Standard \& Poor's, capital outflow only in 2014 amounted to 152 billion dollars (Tuzova \& Qayum, 2015). All of the above leads to a decrease in the productive capacity of the economy, and therefore, reduces the possibility of anti-inflation regulation.

It is also important to understand that consumption processes form the requirements for producers and the economy as a whole. If the country is characterized by a uniformly high rate of consumption, it will also stimulate production. By encouraging the development of effective demand, we stimulate industrial production, which means increase in employment, as well as in capacity utilization rate, etc., and the system begins to operate at full capacity. However, uneven consumption by different social groups can generate and is generating an inflationary potential. In Russia about $90 \%$ of the population uses only half of the consumer goods. The other half is consumed by a group with high income, it is accounting for only about $10 \%$ of the population. The basis of consumption is satisfaction of primary short-term needs; it allows drawing a conclusion about poor savings. The savings of high income group go mainly to the foreign market and do not exert demand pressure on the domestic market. Such a non-optimal structure of consumption reduces the production potential of the economy and increases inflationary pressures. In addition, an essential part of consumption is imported. This is a direct deduction from the income of domestic producers, as well as savings in cash, typical of the Russian population. Thus, producers do not receive the planned profit on produced products and as the result lack means of payment. This leads to a rise in the cost of credit, its inaccessibility and a reduction in the working capital of producers. It may result in the reduction of production and an increase of production costs.

So, at the stage of consumption, inflation manifests itself in sub-optimal proportions of forms of consumption, which, in turn, can contribute to the strengthening of the inflationary process, reducing the production potential of the economy.

\section{Conclusion}

Thus, the specificity of modern inflation lies in the fact that it is built into the reproduction process and cannot be considered outside the economic system as a whole. Therefore, a separate analysis of inflation, income generation and production is fundamentally insubstantial. All these three processes are not independent; they are only elements of a single reproduction mechanism. A thorough study of the real causes of inflation is necessary to improve the effectiveness of state policy, not only in preventing and containing the already inflated prices, but also in other aspects of economic policy. (Kirillovskaya, 2016) This requires a systematic approach to the analysis of inflation processes, taking into account that inflation in its inception and development covers all stages of the reproductive process. On the one hand, it exerts a certain influence on each of them, on the other hand it itself is 
subjected to the reverse action from each stage of the reproductive process. Such an approach allows for the revealing of a variety of the factors generating inflation and influencing the character of its course. Many conflicting theories and concepts of inflation are brought into conformity. Within the framework of the approach, the most adequate mechanisms of anti-inflationary policy can be worked out, taking into account not only economic, but also social, and many other determinants.

\section{References}

Domashchenko, D. (2016). Correlation between Economic Growth, Oil Prices and the Level of Monetization of Economy in Oil and Gas Exporting Countries: Challenges for Russia. Economic and Social Changes: Facts, Trends, Forecast / Ekonomicheskiye i sotsial'nyye peremeny: fakty, tendentsii, prognoz, vol. 1 (43), pp. 96-107. WOS: 000371913400007

Kirillovskaya, A.A. (2016) The Newest Economic Policy, Government Regulation of the Economy and Economic Security. Globalization and its Socio-Economic Consequences. 16th International Scientific Conference Proceedings. ZU - University of Zilina, 5th -6th October 2016, Rajecke Teplice, Slovak Republic. Pp. 870-875. WOS:000393253800108

Kotcofana, T. (2007). The Components of Inflation: the Reproductive Approach. Vestnik of Saint-Peterburg University. Ser.5: Economics, vol. 4, pp. 41-50. RSCI: 16531561

Nusratullin, V.K. (2010) Rentnaya teoriya inflyatsii [Rental theory of inflation]. Ufa: Eastern Economics, Law and Humanities Academy

Pashkus, V.Y. (2016) Evaluation of City Brand in the Global Economy: Techniques and Perspectives. Globalization and its Socio-Economic Consequences. 16th International Scientific Conference Proceedings. ZU - University of Zilina, 5th -6th October 2016, Rajecke Teplice, Slovak Republic. 2016. Pp. 1635-1641. WOS:000393253800202

Pressman, S., \& Holt, R.P.F. (2008) Nicholas Kaldor and cumulative causation: Public policy implications. Journal Of Economic Issues, vol. 42, iss. 2, pp. 367-373. WOS:000256876700008

Protasov, A.Yu. (2011) Inflation in the Economy of the USSR: Nature, Cyclical Trends, Lessons for Modern Russia.// Vestnik of Saint-Peterburg University. Ser.5: Economics, vol. 4, pp.116-129. RSCI: 17037732

Shershnev \& Larionov (1999) Prodovol'stvennyy rynok SSHA, kak spetsializirovannaya sistema sbyta [The US food market as a specialized sales system]. Food Industry, №1. C. 43 - 51.

Tsatsulin, A. N., Babkin, A. V., \& Babkina, N. I. (2016). Analysis of the Structural Components and Measurement of the Effects of Cost Inflation. Vision 2020: Innovation Management, Development Sustainability, And Competitive Economic Growth, 28th International Business-Information-Management-Association Conference. Seville, Spain, Nov 09-10, I - VII, pp. 1559-1573. WOS:000392785700157

Tuzova, Y., \& Qayum, F. (2016). Global Oil Glut and Sanctions: The Impact on Putin's Russia. Energy Policy, vol. 90, pp. 140-151. https://doi.org/10.1016/j.enpol.2015.12.008. WOS: 000370104500014

Xiang Baolin, \& Xiao Xiaoyong. (2009). Study on the Effect of Minimum Wages in China. Proceedings Of The 4th International Conference On Product Innovation Management, Wuhan, PEOPLES R CHINA, Aug 22-23, I, II, pp. 11261131. WOS:000271211500208 